\title{
Using Customer Characteristics to Manage Marketing and Revenue Management Activities
}

\author{
Stepan Chalupa ${ }^{1}$, Martin Petricek ${ }^{2}$ \\ ${ }^{1}$ Univerzity of Hradec Králové, Rokitanského 52, 15100, Hradec Kralove, Czech Republic \\ ${ }^{2}$ The Institute of Hospitaltiy Management in Prague, Svidnicka 506, 18100, Prague, Czech Republic
}

\begin{abstract}
Understanding customer behaviour is an essential activity for hotel marketers and revenue managers. This article presents the statistical approach based on the data mining techniques focused on the extraction of valuable insight from big data. Using Two-Step Clustering, four major customers segments were identified, including their characteristics. Their description based on the booked room type, rate plan, booking window, net average room rate and length of stay can help the manager to plan better their activities.
\end{abstract}

Keywords - Market segmentation, cluster analysis, Two-Step Cluster, Hospitality marketing, Revenue Management

\section{Introduction}

Current research in the field of hospitality marketing and revenue management is focusing on product pricing, mainly the approaches towards dynamic pricing. Several authors are defining the whole process of revenue management as a revenue maximization process of selling the right product at the right time with the right price in the right place [1],[2].

DOI: 10.18421/TEM93-33

https://doi.org/10.18421/TEM93-33

Corresponding author: Stepan Chalupa,

Univerzity of Hradec Králové, Rokitanského 52, 15100,

Hradec Kralove, Czech Republic.

Email: chalupa@vsh.cz

Received: 25 April 2020.

Revised: 08 July 2020.

Accepted: 18 July 2020.

Published: 28 August 2020.

(cc)BY-NC-ND 2020 Stepan Chalupa \& Martin Petricek; published by UIKTEN. This work is licensed under the Creative Commons Attribution-NonCommercial-NoDerivs 4.0 License.

The article is published with Open Access at www.temjournal.com
Ivanov \& Zhechev [3] point out that price-setting and overall revenue management are influenced by the possibility of making an advanced booking, the ability to manage price variation across the time and mainly by market segmentation, the homogenous groups of customers with shared characteristics heterogeneous to other customer groups.

Dolnicar [4] points out that market segmentation is essential for understanding the customers need and wants and connected marketing activities.

Proper knowledge of customer groups and their characteristics can be further used within price setting, which can differ in the booking horizon, in different situations and for a different customer segment. [5] The same product can be sold for diametrically different rates with diametrically different conditions. This is called price discrimination, which can occur in three different levels (1) total price discrimination, in which the marketer focuses on single individual customers based on the knowledge of his demand curve, (2) segment discrimination, where the marketer knows the common characteristics of a group of customers and thanks to comprehensive strategy the migration among other segments can be prevented and (3) indirect discrimination, in which the product attributes differ within the different segments offer. [6]

Vives, Jacob \& Payeras [1] propose the structure of hotel market segmentation and key factors to consider when segmenting the market. The internal and external market segmentation is defined. The internal segmentation focuses mainly on the factors that can be directly controlled and affected by the hotel revenue managers or other employees [7] like booking dates, rate fences, customer type and demand seasonality. External segmentation factors cannot be managed in short-run and are derived from other hotel operations characteristics and activities [8] like hotel characteristics, systems used, distribution channels used.

The main focus of this study is in the proper understanding of customer booking behaviour with 
an emphasis on the price-sensitive transient market segment. The two-step cluster analysis is used to reveal the hidden behavioural patterns within online bookings made by seaside resort customers. The output of this study can be used for planning various marketing activities and revenue management optimization.

The uniqueness of this study lays within the use of empirical behavioural data of hotel customers. Many previous studies used primary data collected by questionnaires with lack of internal and external validity measure applied. This shows the need for the use of hard data that cannot be modified and bias if the standard procedures are applied and followed.

\section{Literature Review}

As proposed by Dolnicar [4], a proper understanding of customers is essential for hotel operations. Various approaches for market segmentation were proposed by Vives, Jacob \& Payeras [1] in the previous section. Customers are commonly divided into two major groups by their travelling or booking motive, the leisure and business [9], wherefrom the revenue management perspective; the business segment is price-insensitive due to negotiated rates and conditions. The rates are negotiated or bided through RFPs (Request For Proposal) for a certain period for big companies or offered by sales managers with minor pricing restrictions (opaque discounting). The leisure segment is more price-sensitive due to the perception of values. These customers use their funds (not to corporate budget) to receive the value. From this perspective, they investigate the offer in more details and compare it to other offers by competing hotels. This differentiation, in the sense of further application, is too general and differentiation within groups and individuals should be applied. [10]

This leads to the creation of four major market segment with specific characteristics.

- Business Groups (MICE segment) with a predefined budget and structure of the demanded services. From the perspective of dynamic pricing, this segment is highly insensitive to rate changes within the hotel. This group consumes a wide range of services (not only the accommodation), and the offers are individually negotiated.

- Business Individuals (corporates) with negotiated static of semi-dynamic rates.

- Leisure Groups (tours and business through tour operators) with negotiated rates and allocated rooms for a specific period (mainly for high leisure season). These negotiated rates are lower than publically visible rates as the TO is combining the accommodation with other services to attract the customers with a comprehensive offer.

- Leisure Individual (Frequent Individual Traveller of Transient) with non-negotiated rates. This segment can be directly influenced by dynamic rates usage in the short term.

According to Crawford-Welschs [11] meta-study, the market segmentation in the hospitality industry can be done using several approaches, a priori segmentation, post-hoc segmentation, flexible segmentation and componential segmentation. The post-hoc segmentation approaches are used to analyse the collected data and use them for product and price optimization. As proposed by Ha \& Park [12] and Ivanov, Mikinac \& Perman [13], hoteliers should use the collected customer data to reveal hidden behavioural patterns and used them not only within CRM (Customer Relationship Management) but as well for other marketing activities to reach higher customer value and business profit.

Dursun \& Caber [14] use the customer buying characteristics to create the market segments based on the RFM analysis, where they focus on 362 randomly selected hotel quests from the loyalty membership program. The results are directly influenced by loyalty program membership (not all the clients are members of this program) and consider mainly the most recent hotel booking, frequency of transactions and total amount spend within a specific period. Customer demographics and geographic characteristics are used only for the description of identified segments.

Hadjikakou et al. [15] are using the data from „,exit survey" that consists of destination visitors spending behaviour description, including demographics and other characteristics. The segmentation is done using the naïve method of distribution clustering based on the total amount of money spend.

Sainaghi, Mauri \& d'Angella [16] are using STR (Smith Travel Research) hotel performance daily data to understand the effect of leisure, business and event segments on the total hotel market performance.

Guttentag et al. [17] use empirical data collected by online questionnaires about 844 AirBnB users about their socio-demographics and travelling behaviour with main focus on the travelling frequency and other characteristics. Using a wide range of methods (ANOVA, Welsch Test, Chi-square and Factor Analysis) the authors identified following market segments: Money Savers, Home Seekers, Collaborative Customers, Pragmatic Novelty Seekers, and Interactive Novelty Seekers.

Nurjannah et al. [18] use Two-Step Clustering of data focused on the perception of destination and individual satisfaction, including demographics. Using the log-likelihood measure, they identify two 
segments of destination visitors. The same Two-Step Cluster methodology was as well used by Borges Tiago et al. [19] who investigated main decision making characteristics of destination visitors, individual factors influencing revisiting the destination, information sources and general methods used for holiday organization. The authors used data from 31122 telephone interviews with EU citizens.

The use of clustering methods is common for datadriven segmentation. The benefit of using the TwoStep Cluster is in a combination of nominal and numerical variables for clustering. Other researchers used as well Wards Clustering Method [20], Kmeans [21],[22] or naïve clustering based on the predefined variable as its distribution [24].

Lee et al. [21] use the clustering analysis to reveal common characteristics of casino visitors. The data collected from 399 gamblers/casino visitors consisted of data about their behaviour (length of stay, expenditures for specific services within the casino resort, level of satisfaction) and demographics for segment description.

\section{Data and Methodology}

Using modern IT solutions, hoteliers can aggregate customer behavioural data or transactional data from various resources. For this study, the channel management tool RezGain was used for data collection. Channel management tools are used for inventory, price and price restriction bulk management. The whole system is connected to online booking platforms (mainly OTAs and Web Booking Engine). For this study, API connection was created with Booking.com, Expedia.com, Agoda.com (Booking Holding brand), Orbitz.com (Expedia Group brand) and Splendia (Expedia's corporate online booking tool).

Used transactional data consisted of the following variables:

- ReservationID (including guest identification for returning visitors),

- Booking Date (date when the reservation was created),

- Date of Arrival,

- Date of Departure,

- Room Type Booked,

- Number of Rooms Booked,

- Number of Room Nights (the number of rooms multiplied by the number of booked rooms),

- Rate Plan (including meal information or room flexibility),

- Net Rate (Booking Rate subtracted by the commission level),

- Gross Rate (Booking Rate),

- Guests Nationality,

- Distribution Channel used.
Other variables, like booking window and net average rate, need to be computed. Booking Window is the difference between Booking Date and Day of Arrival in days. Net Average Room Rate is Net Rate divided by The Length of Stay, the difference between Date of Arrival and Departure.

In total, which is 1591 reservations of Seaside hotel resort (transactions) were analysed. As the hotel offers a wide range of services and several unique rooms like Presidential apartment, only the most booked room types were used (Standard Double Room, Deluxe Double Room, Double Room with Sea View and Historical Double Room).

The data set consists of several types of variables which leads to the selection of clustering methods that can use both nominal and numerical data. As proposed by several authors [18],[19], Two-Step Clustering Methods was selected. Dolnicar [23] describes the characteristics of data-driven market segmentation in her perspective paper, in which the researchers should approach this research as strictly exploratory. The high-quality data in respective amount are the essential part of the research, and researchers should avoid data pre-processing (for example, using factor analysis) or ordinal data. To reach the best results, researchers should as well use only uncorrelated data.

The whole process of clustering is based on the finding of the cluster with the highest internal homogeneity and higher external heterogeneity. The heterogeneity of clusters is being measured as the difference between the centres of the clusters using the following distance measure

$$
d_{V M}\left(C_{h}, C_{h^{\prime}}\right)=\xi_{\left\langle h, h^{\prime}\right\rangle}-\left(\xi_{h}+\xi_{h^{\prime}}\right) \text {, }
$$

Where the intercluster variability $\left(\mathrm{d}_{\mathrm{VM}}\right)$ is being described as the difference between the variance of connected clusters and their sum.

To measure the distance between numerical data, Euclidian distance is being used. When using nominal and ordinal data, following log-likelihood distance measure should be used.

$$
\xi_{g}=n_{g}\left(\sum_{j=1}^{p^{(1)}} \frac{1}{2} \ln \left(\mathrm{s}_{\mathrm{j}}^{2}+\mathrm{s}_{\mathrm{gj}}^{2}\right)+\sum_{j=1}^{p^{(2)}} H_{g j}\right)
$$

Within this equitation, a number of members within the $\mathrm{g}$-cluster is being represented by $\mathrm{n}_{\mathrm{g}}, \mathrm{p}^{(1)}$ is the number of numerical variables and $\mathrm{p}^{(2)}$ the number of nominal variables. The variance of numerical variables $\left(s_{j}{ }^{2}\right.$ for $\mathrm{j}$-variable and $\mathrm{s}_{\mathrm{gj}}{ }^{2}$ for $\mathrm{j}$ variable in $\mathrm{g}$-cluster) and the entropy $\mathrm{H}_{\mathrm{gj}}$ of nominal variable $\mathrm{j}$ in $\mathrm{g}$-cluster are used to measure the distance between there clusters.

For the verification of cluster membership, Bayesian Information Criterion was selected. 


\section{Results}

Table 1. Cluster characteristics after Two-Step Clustering

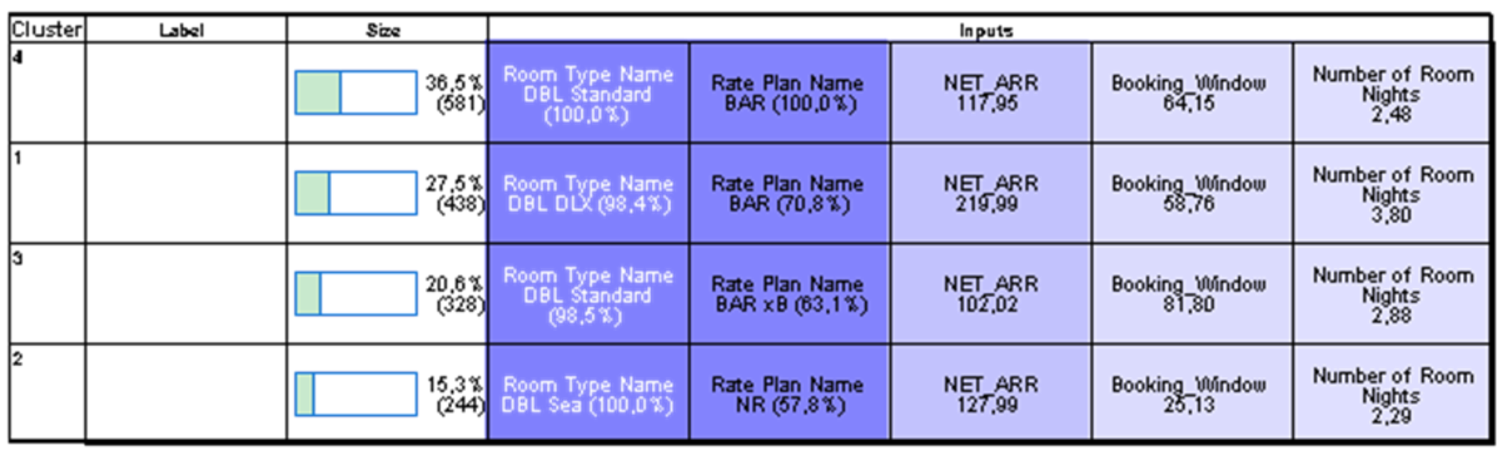

Using the previously mentioned data and methodology, the study shows the results of this clustering approach. For clustering, five variables were selected. The Room Type Name, Rate Plan (Advance Purchase, Best Available Rate - BAR, BAR with Half Board, Minimum Length of Stay MLOS, Non-Refundable, Opaque and Super Saver), Net Average Room Rate, Booking Window and Number of Room Night, the length of stay. As the Two-Step clustering reached Fair cluster quality, it is important to show the predictor importance. Figure 1 shows the predictor importance for final cluster membership.

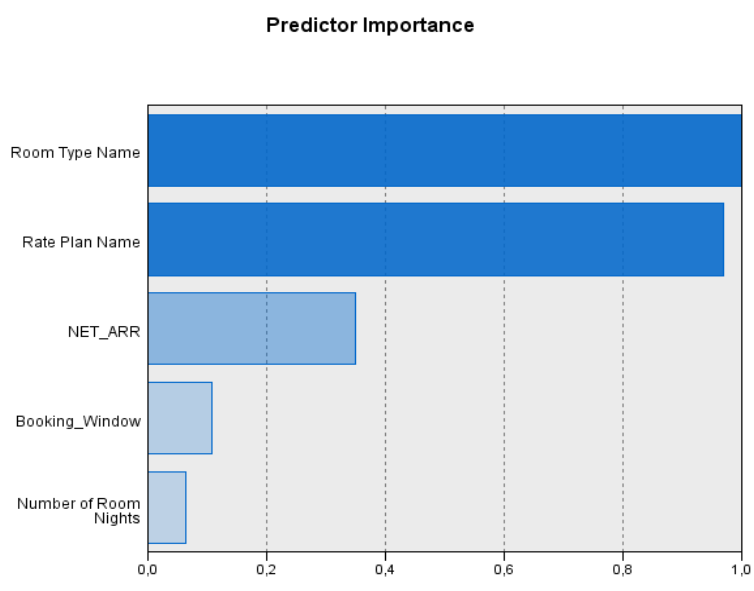

Least Important

Most Important

Figure 1. Clustering predictor importance visualization

The nominal variables are listed as the most important variables which prove the still working hedonic segmentation based on the product characteristics and its variations. While clustering using numerical variables, the Net Average Room Rate is the most important one.

In total, 4 clusters were identified, and Figure 2 describes the distribution of cases within these clusters.

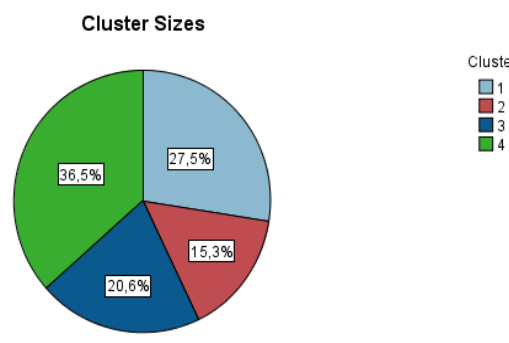

Figure 2. Cluster sizes

Table 1 describes the centroids (central nodes) of identified clusters sorted by the size of the cluster (included cases).

- Cluster 4. The largest segment of flexible clients who book their standard stay for 2-3 nights with 64 days long booking window. These customers can be described as the personas (the average customers) of the resort. Using mainly standard bed $\&$ breakfast offer without other offers.

- Cluster 1. Luxus seekers who are paying the highest rates to enjoy the highest standard of service. Their characteristics nearly in common to the previous cluster, but these clients are using extra rate plans with included extra services.

- Cluster 3. Best deal seekers, who use mainly BAR without breakfast, Super Savers and Advance Purchase rate plans. This segment is planning the stay nearly 90 days before the arrival. These clients are fully decided about the destination and seek for the best available offer. As well they are worried about the possibility of losing such a good deal.

- Cluster 2. The smallest cluster that consists only of 244 cases $(15,3 \%)$ and the majority of NonRefundable rate plans are selected. This cluster can be identified as decided travellers. They are willing to exchange the non-existence of cancellation policy (after the cancellation, the prepaid reservation is not refunded) for a relatively lower rate for the booking window of 25 days. These clients prefer a double room with Sea View. 


\section{Conclusion}

The results of this study can be used while planning the marketing and revenue management activities of the selected Sea Side resort as well as any other hotel. The procedure of using stored and easily accessible data are bringing valuable insight into transient segment behaviour. Using the TwoStep clustering and transactional data should improve the data-driven management of hotel operations.

Detailed characteristics of identified clusters (customer segments) should be used to timely plan the prices and the restriction as well as the communication or product differentiation.

In comparison to previous studies, this article shows a more comprehensive way of customers segmentation which cannot be biased by the anonymous respondents. As well, the validity of this research is higher as the data can be used on the level of the whole population, not only on the level of the sample. From the methodological point of views, this approach should bring more value and better results.

Further research should use more reservations and more variables in order to improve the quality of results as an input for management decision making.

\section{References}

[1]. Vives, A., Jacob, M., \& Payeras, M. (2018). Revenue management and price optimization techniques in the hotel sector: A critical literature review. Tourism Economics, 24(6), 720-752. doi: $10.1177 / 1354816618777590$.

[2]. Abrate, G., Nicolau, J. L., \& Viglia, G. (2019). The impact of dynamic price variability on revenue maximization. Tourism Management, 74, 224-233. doi:10.1016/j.tourman.2019.03.013.

[3]. Ivanov, S., \& Zhechev, V. (2012). Hotel revenue management-a critical literature review. Turizam: međunarodni znanstveno-stručni časopis, 60(2), 175197.

[4]. Dolnicar, S. (2002). Business travellers' hotel expectations and disappointments: a different perspective to hotel attribute importance investigation. Asia Pacific Journal of Tourism Research, 7(1), 29-35. doi:10.1080/10941660208722107.

[5]. Wu, C. C., Liu, Y. F., Chen, Y. J., \& Wang, C. J. (2012). Consumer responses to price discrimination: Discriminating bases, inequality status, and information disclosure timing influences. Journal of Business Research, 65(1), 106-116. doi:10.1016/j.jbusres.2011.02.005

[6]. Png, I. (2013). Managerial economics. Routledge.

[7]. Kim, M., Lee, S. K., \& Roehl, W. S. (2016). The effect of idiosyncratic price movements on short-and long-run performance of hotels. International Journal of Hospitality Management, 56, 78-86. doi:10.1016/j.ijhm.2016.04.006.
[8]. Talluri, K., \& Van Ryzin, G. (2004). Revenue management under a general discrete choice model of consumer behavior. Management Science, 50(1), 1533. doi:10.1287/mnsc.1030.0147.

[9]. Gallego, G., \& Van Ryzin, G. (1994). Optimal dynamic pricing of inventories with stochastic demand over finite horizons. Management science, 40(8), 999-1020.

[10]. Guadix, J., Cortés, P., Onieva, L., \& Muñuzuri, J. (2010). Technology revenue management system for customer groups in hotels. Journal of Business Research, 63(5), 519-527. doi:10.1016/j.jbusres.2009.04.013.

[11]. Crawford-Welch, S. (1990). An empirical examination of mature service environments and high performance strategies within those environments: The case of the lodging and restaurant industries (Doctoral dissertation, Virginia Tech).

[12]. Ha, S. H., \& Park, S. C. (1998). Application of data mining tools to hotel data mart on the Intranet for database marketing. Expert Systems with Applications, 15(1), 1-31.

[13]. Ivanovic, S., Mikinac, K., \& Perman, L. (2011). CRM development in hospitality companies for the purpose of increasing the competitiveness in the tourist market. UTMS Journal of Economics, 2(1), 5968.

[14]. Dursun, A., \& Caber, M. (2016). Using data mining techniques for profiling profitable hotel customers: An application of RFM analysis. Tourism management perspectives, 18, 153-160. doi:10.1016/j.tmp.2016.03.001.

[15]. Hadjikakou, M., Chenoweth, J., Miller, G., Druckman, A., \& Li, G. (2014). Rethinking the economic contribution of tourism: case study from a Mediterranean Island. Journal of Travel Research, 53(5), 610-624.

[16]. Sainaghi, R., Mauri, A., \& d'Angella, F. (2019). Decomposing seasonality in an urban destination: the case of Milan. Current Issues in Tourism, 22(16), 1919-1924.

[17]. Guttentag, D., Smith, S., Potwarka, L., \& Havitz, M. (2018). Why tourists choose Airbnb: A motivationbased segmentation study. Journal of Travel Research, 57(3), 342-359.

[18]. Budi Astuti, A., Achmad Rinaldo Fernandes, A., Amaliana, L., Yanti, I., \& Isaskar, R. (2019). Two Step Cluster Analysis for Tourist Segmentation Coastal Object for Green Marketing Strategy. E\&ES, 239(1), 012019.

[19]. Tiago, M. T. P. M. B., de Almeida Couto, J. P., Tiago, F. G. B., \& Faria, S. M. C. D. (2016). Baby boomers turning grey: European profiles. Tourism Management, 54, 13-22.

doi:10.1016/j.tourman.2015.10.017

[20]. Chung, K. Y., Oh, S. Y., Kim, S. S., \& Han, S. Y. (2004). Three representative market segmentation methodologies for hotel guest room customers. Tourism Management, 25(4), 429-441. doi:10.1016/s0261-5177(03)00115-8 
[21]. Lee, C. K., Lee, Y. K., Bernhard, B. J., \& Yoon, Y. S. (2006). Segmenting casino gamblers by motivation: A cluster analysis of Korean gamblers. Tourism Management, 27(5), 856-866. doi:10.1016/j.tourman.2005.05.009.

[22]. Jang, S. C., Morrison, A. M., \& T O’Leary, J. (2002). Benefit segmentation of Japanese pleasure travelers to the USA and Canada: selecting target markets based on the profitability and risk of individual market segments. Tourism management, 23(4), 367-378. doi:10.1016/s02615177(01)00096-6.
[23]. Dolnicar, S. (2019). Market segmentation analysis in tourism: a perspective paper. Tourism Review. https://doi-org.ezproxy.lib.cas.cz/10.1108/TR-022019-0041.

[24]. Mok, C., \& Iverson, T. J. (2000). Expenditure-based segmentation: Taiwanese tourists to Guam. Tourism management, 21(3), 299-305.

doi:10.1016/s0261-5177(99)00060-6. 